\title{
Art History and the Modern in Southeast Asia
}

\section{Pamela N. Corey}

To cite this article: Pamela N. Corey (2020) Art History and the Modern in Southeast Asia, Art Journal, 79:1, 116-119, DOI: 10.1080/00043249.2020.1724039

To link to this article: https://doi.org/10.1080/00043249.2020.1724039

$$
\text { 曲 Published online: } 26 \text { Feb } 2020 .
$$

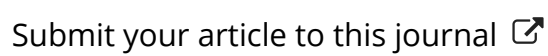

Q View related articles $₫$

View Crossmark data $[\pi$ 
a French paramilitary terrorist group, the Organisation Armée Secrète (OAS). A structure designed to perpetuate the violence of colonial rule in this moment becomes the rubble of war. Here one wishes Henni would pick up its pieces with attention to the semantic transformations that Allais addresses.

Despite their different leanings, read together these books reveal the extraordinary wealth of documentation and representation of architecture that lies in the dusty files of bureaucratic archives. Among many revelations, they show how wartime is less a hiatus in spatial production than a moment of slippage in accepted ways of utilizing its potential. In both titles, the graphic material is reproduced at small scale, but to address this limitation Allais has placed some drawings online (http://we-aggregate.org/piece /the-design-of-the-nubian-desert), and Henni has curated a remarkable traveling exhibition of planning and propaganda images, Discreet Violence: Architecture and the French War in Algeria. These visual narratives are remarkably powerful in demonstrating the range of media used in these other forms of architecture, creating transformation potentials for practice at large. As architectural work embraces broader diversity through new professional identities, sites of impact, and communicative strategies, such histories matter deeply for uncovering its overlooked connections and consequences.

Hannah le Roux is an architect, educator and curator. Her work in all these areas revisits the modernist project in architecture in Africa and considers how its transformation through the agency of Africa presents a conceptual model for contemporary design. From a Southern African perspective, she considers how apartheid and colonial constructions erase and are overlain by other human actions. She has written on these dynamics for Blank: Architecture, Apartheid and After (Rotterdam, Netherlands: NAi Publishers, 1999); Trade Routes: History and Geography, 2nd Johannesburg Biennale (Johannesburg: Greater Johannesburg Metropolitan Council, 1997); Afropolis: City, Media, Art; and the Journal of Southern African Studies; curated exhibitions in Johannesburg, Venice, Brussels, and Rotterdam; and engaged with the spatialities of diaspora coffee ceremonies and the soccer culture of earth fields through design research. In 2017 she was a principal candidate in the Fulbright African Research Scholar Program and a research fellow in the Canadian Centre for Architecture/Mellon Foundation project Architecture and/for the Environment.
Pamela N. Corey

\section{Art History and the} Modern in Southeast Asia

T. K. Sabapathy. Writing the Modern: Selected Texts on Art and Art History in Singapore, Malaysia, and Southeast Asia, 1973-2015. Ed. Ahmad Mashadi, Susie Lingham, Peter Schoppert, and Joyce Toh. Singapore: Singapore Art Museum, 2018. $44^{8}$ pp.; 70 color ills., 5 b/w. $\$ 48$

A serious volume testifying to the contributions of T. K. Sabapathy to the field of modern and contemporary Southeast Asian art history seems long overdue, and in this regard, this anthology published by the Singapore Art Museum in 2018 is a welcome development. For the first time, the Singaporean art historian's prolific body of writing, extracted from such sources as newspaper columns, exhibition catalogs, artist monographs, and symposium proceed ings, is presented in a formidable morethan-four-hundred-page compendium of fifty-seven selected texts. The editorial team comprises Ahmad Mashadi (director of the National University of Singapore Museum), Susie Lingham (former director of the Singapore Art Museum), Peter Schoppert (director of National University of Singapore Press), and Joyce Toh (senior curator at the Singapore Art Museum).

The book surveys the development of Sabapathy's grappling with several interrelated inquiries as they have come to shape studies of modern and contemporary art in Southeast Asia over nearly half a century. Interrogated as fields, in terms of Sabapathy's concerns with the nature of their discursive formation and utility, these frameworks may be construed as art history, the modern (and the contemporary), and regionalism. How these topics have been imaginatively, even forensically, explored in Sabapathy's attempt arguably to define a field of study-concomitant with his wariness of definition as an act of prescription-is unparalleled in terms of a scholarly perspective shaped from Singaporean, Malaysian, American, and British institutions. Enriching this body of work is a historical outlook shaped by memories of 1950 s and 1960 s postcolonial fervor in former British Malaya and the respective national projects of newly split Singapore and Malaysia, followed by the Association of Southeast Asian Nations (ASEAN)'s spearheading regional artistic affairs in the I980s and I990s. As much as Sabapathy wrote about art and artists to create the building blocks of an art history, he never ceased to rigorously tackle art's frames of representation, from the written text to the gallery space to the exhibition symposium, highly attentive to his own role in interpellating readers from within these constituent elements at every turn.

Thiagarajan Kanaga Sabapathy, more commonly referred to as T. K. Sabapathy, was born in the British Straits Settlements and began his study of art history as an undergraduate history major at then Singapore-based University of Malaya in 1958, a year after the territories proclaimed independence as the Federation of Malaya. He studied art history as an elective, as no major provision was available, a situation that he laments has not changed. He found the teachings of his art history lecturer, esteemed scholar of Chinese art history Michael Sullivan, deeply influential, and subsequently pursued a master's degree in the history of art at the University of California, Berkeley. He departed for California in 1962 , making the journey by sea. At Berkeley he received training in the classical traditions of art and art historical method, both European and Asian: "The grandeur of history of art as an academic discipline was revealed to me when I commenced studies in Berkeley in the fall of 1962 . The propelling scheme was the survey." 'However, to gain specialist knowledge in Southeast Asian art, he contin ued his studies at the School of Oriental and African Studies in London in the later 1960s, where he undertook research into premodern narrative representations. He continued his studies supported by a research fellowship over two years, while supplementing his income through teaching. ${ }^{2}$ His focus was the classical, and the means of interpretation primarily iconological; when he encoun tered modern art through the divergent approaches of Philip Rawson and Claire Holt, he recounts feeling unequipped, and that "the modern was strange." ${ }_{3}$

With the establishment of an art history course (focusing on modern Malaysian art) at the newly launched Universiti Sains Malaysia in 1970, Sabapathy returned to Southeast Asia to take up a post as a lecturer. 
He undertook the significant challenge of creating a curriculum and body of teaching materials from scratch, from foraging for teachable writings to photographing artworks to create lecture slides. As part of this endeavor, he frequently collaborated with celebrated Malaysian artist and critic Redza Piyadasa: "Our early writings on art and artists in Malaysia were collected and published in 1982. In them are also nuclear attempts at ascertaining the modern in this region, critically and historically. Hence I began involvement with the modern and have largely stayed with it, since I could no longer traverse parallel worlds. Indeed, I had to turn away from one of them effectively, returning intermittently." ${ }^{4}$ Sabapathy returned to Singapore in 1980, where he began contributing to the Straits Times until he ceased writing art criticism-in that form-in 1993. In 198I he was appointed lecturer in the history of art in the department of architecture at the National University of Singapore, where he has continued to teach to this day.

As one of the editors, Peter Schoppert, notes, "The goal in republishing a set of Sabapathy's writings in an anthology and mapping them against different themes, and against a timeline of changing art practices and institutions, is to heed Sabapathy's call to begin the hard work required to build the foundation for a more historically aware and regionally grounded practice of art writing" (225). Writing the Modern is organized into four sections, following opening materials that include a foreword, an editors' preface, short editorial notes by Chu Chu Yuan, and an introduction authored by Ahmad Mashadi. Each of the four sections is introduced by a short essay that provides the editorial rationale for the selection of texts. Within each section, the texts are organized chronologically, from earliest to most recent, to give a sense of Sabapathy's development of a methodological inclination over time. The book concludes with a timeline of all his writings. Unfortunately, images are scarce and are reproduced at an almost thumbnail scale, which leaves the reader feeling somewhat bereft in the face of Sabapathy's committed formalist scrutiny of the artwork.

The first section, "The Southeast Asian Artist in Relation to Art History," with an editorial overview by Joyce Toh, features Sabapathy's writings about individual artists, extracted from monographs, exhibition reviews, newspaper columns (the "Art and Artists" feature in the Straits Times), and catalog essays. The first essay - the 1978 "Towards a Mystical Reality” from his monograph on Piyadasa-is of major significance for his theorizing of what many consider to be an example of the earliest conceptual practices in

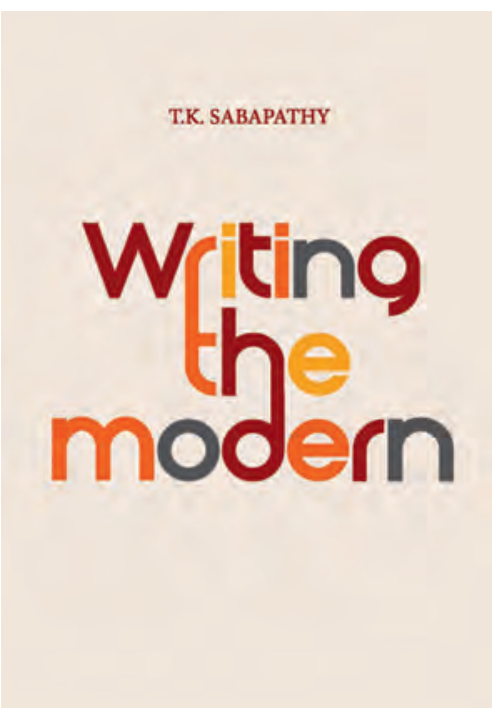

Southeast Asia. Other artists covered include those affiliated with the Nanyang artists, such as Lim Hak Tai, Cheong Soo Pieng, and Georgette Chen, and those celebrated as heralding the contemporary, including Tang Da Wu and Cheo Chai-Hiang. The span is wide, in terms of both the period covered and the spectrum of practices that are articulated as illustrating the modern or the contemporary. This is one challenge to the volume's coherence in its framing of the modern: many of Sabapathy's essays articulate the contemporary, and the conditions for such a distinction from-and its glossing with — the modern are not clearly addressed by the editors within the book's purview.

The first section does illuminate how “Sabapathy's interest in biography as a means and method of writing art history arches back to a practice with centuries-old historical roots, in both Western and Asian art“ (30), demonstrating his sourcing of familiar and unfamiliar methods to navigate what was a new field of art historical representation not only in Southeast Asia. ${ }^{5}$ For Sabapathy, "It was a way of writing [that was] unlike the historical traditions of art in which I was schooledto write on the modern was also to write on the artist" (3I). Important topics introduced in this section, and recurring throughout the book, include the figure of Malaya in the artistic imagination, the centrality of art in the cultural debates in the 1950s and 1960s in the British postcolonies, and the context of Singapore's divorce from historical traditions to realize its ideology of "installing the modern/new at the very centre of its strategy"

( I IO). Witnessing such a claim to tabula rasa would appear to have fueled Sabapathy's own commitment to historicization, and to connect to premodern models to conjecture on regional hypotheses in the present.

The second section, "A Mind for Method, and an Eye for Medium, Materiality, and Form," with an editorial overview by Susie Lingham, highlights Sabapathy's sensitivity to artistic process and the problem of medium. These issues are relayed through writings on artworks grounded in such mediums as drawing, sculpture, ceramics, and installation, which further illustrate aspects of artistic formation responsive to site, mobilities, personal and professional relationships, institutions, and alternative forms of education. One example is an analysis of new approaches to artmaking by Sulaiman Esa and Piyadasa, whose conceptual orientations were significantly shaped by their studies in Britain when major shifts in artistic pedagogy were taking place. ${ }^{6}$ While some of the emphases in this section would appear to repeat those of the first, a distinguishing feature is Sabapathy's consideration of the vantage points offered through medium-based discourses attached to both classical art and modernism: "I have leaned towards texts on sculpture in the Anglo-Saxon critical tradition that open up paths along which one can traverse in order to approach sculptural practices and ideals here and offer explanations for them" (194). This strategy is reiterated as a first point of recourse in what he describes as an ahistorical state of artistic discourse in both Singapore and Malaysia: "If one of the features identifying the modern artist is in the adoption of a critical and self-regulating stance towards traditions as such, then the modern artist in Malaysia must also embrace the tradition of the new as it has been personified in this country. Ignorance of it may well produce a context that is sterile" (I7I). The third section, "Art Institutions and the Exhibition," with an editorial overview by 
Peter Schoppert, focuses on Sapapathy's writ ing for and about exhibitions and exhibitionmaking institutions. A salient feature within this group is Sabapathy's trenchant commitment to wide-reaching politico-cultural critique. In response to the rise of region-facing projects vis-à-vis the ASEAN cultural agenda, Sabapathy challenged the hollowness of such endeavors as diplomatic lip service:

Exhibitions are acts of avowal and engagement, and the curator assumes a formative role in these processes. In this regard, the ASEAN exhibition has not fulfilled its role. There are three objectives underpinning this enterprise. I have mentioned one-consciousness. The other two are the provision of a base for comparative study and a glimpse of cultures of the countries. Comparative bases for study have to be structured and continually tested. Glimpses need positions of advantage. These are means by which what has been produced is rendered intelligible, sensible. ... So far, curators in the ASEAN shows have been coy. (237)

His desire to see more substantial critical thinking on regional representation of and from within Southeast Asia is strongly emphasized throughout this and the following section. However, of importance here is his elaboration of the exhibition as a crucial vehicle through which regional propositions can be tested. Other essays demonstrate Sabapathy's holding of national institutions to account for the lagging development of art history as a public resource: "[The National Museum Art Gallery] cannot avoid this responsibility. It has to purchase such works and not depend on donations by artists. Only then can it begin to shape the history of art in Singapore, and thereby fulfil its role" (242).

The fourth section, "Regionalist Perspectives in Southeast Asian Art," with an editorial overview by Ahmad Mashadi, draws out an enduring preoccupation in Sabapathy's writing, but because the question of region appears throughout the book, thematic isolation feels somewhat unnecessary. Sabapathy frequently invited regional hypotheses through historiographical analyses, drawing on the works of celebrated scholars, such as Georges Coedès and Ananda Coomaraswamy, and art, for instance by returning to the Nanyang and regionality within the nation. Mashadi attributes the how and why of this preoccupa- tion to Sabapathy's own itinerant academic formation and to his scrutiny of art's alignment with national horizons: "Sabapathy distinguishes modern art history from the national, reminding his readers that discernable and coherent developments started well before Malaysia's independence in 1957"

(333). Mashadi refreshingly situates Sabapathy among a rising community of art historians in I990s Southeast Asia producing what today are considered foundational studies, yet the question of cross-border research remained elusive for Sabapathy:

How do we perceive the region today, and how do we perceive it art historically? Or is the quest for a regionalist perspective a futile, self-defeating quest? I ask this question because there is a pronounced tendency for art writers/ scholars in Southeast Asia to focus on the constituent parts of Southeast Asia rather than to develop a perception of the region as a whole and as a suitable object of study. (376)

In a parallel deconstructive endeavor to that undertaken by scholars rethinking "the West" or "Europe," Sabapathy similarly analogizes Europe as a regional construct:

As an issue, region and regionness have historical and current pertinence for Europeans. Indeed, it reaches into and shapes mythological domains. ... The euro as currency presupposes that there are capacities and symbolic means for narrating Europe as an integrated region. It marks an ascendency of region-ness over nation-states as nominal construc tions. $(393)^{7}$

This is a unique volume in that there are no comparable anthologies by a single author devoted to writing about modern and contemporary Southeast Asian art as a field of study. ${ }^{8}$ The editors are to be seriously commended for the task of compiling such a wealth of materials into an invaluable resource for researchers of Southeast Asian art. To some extent, an engagement with Sabapathy's writings as categorized through the themes selected here enables the parsing of certain discursive priorities and the ways in which they beckoned deeper engagement from what we might assume to be a regional readership at the time of their production. However, Sabapathy's writings were often prescient queries into disciplinary and interdisciplinary problems beyond the region, such as those that lie at the intersection of art history and the decolonial project. As such, it is tempting to imagine what other forms the anthology might have taken to more closely align with Sabapathy's intellectual ambitions.

One avenue might have been through a retooling of the editorial themes. Despite the editors' respective efforts to distinctively foreground the overarching tenor of each section, the effectiveness of this mode of organization is uncertain. In Mashadi's introduction to the volume, he notes that some of these texts are iterations that have evolved over time, where passages may reappear, albeit somewhat repurposed, contextualized within and in relation to specific circumstances of their delivery and intentions. As a collection of Sabapathy's writings rationalized along key subjects or interests, this publication also hopes to construct grounds on which the texts may converse with and be regarded in relation to other texts written variously by other writers and historians, including his contemporaries. (19) The breadth of writings compiled here is both an asset and a challenge. Those less familiar with Sabapathy's work may have difficulty mining the book for conceptual threads given the extent to which the abovementioned themes recur across so much of his writing and in diverse forms (e.g., from newspaper columns to lengthy monograph essays). The extensive overlaps across the sections undermine the coherence of separate themes, as Sabapathy's writings wove together compelling strains of inquiry that should be seen as the warp and weft of the same fabric of discourse rather than thematically segregated.

A more challenging alternative-or perhaps a future prospect-may have been to focus on a more tightly curated selection of more substantial texts so that each could evince a more unique identity, a legibly individualized offering to the field. An example would be the omitted 1996 essay "Developing Regionalist Perspectives in Southeast Asian Art Historiography," published in the cata$\log$ for the second Asia Pacific Triennial of Contemporary Art. The essay consolidates sections of several texts included in the vol ume, and demonstrates Sabapathy's finely honed thinking on historiography in critical response to a perceived nativist turn in 
the theorizing of the modern within Asia. It furthermore stands out as an excellent resource for teaching. The significance of the essay's contribution, and that of others, could be explored through more specific editorial annotation or through partnered responses by interlocutors in the field of Southeast Asian art history and beyond - for example, an art historian of China (perhaps another former student of Michael Sullivan) reflecting on the Nanyang within Chinese art historiography, or another scholar preoccupied with the question of regionalism in Asian art history, and so on. Perhaps such a project could be the next step in furthering Sabapathy's historiographical pursuits while constructing the grounds for continued conversation.

Pamela N. Corey is an assistant professor of Southeast Asian art at SOAS University of London. She is currently completing a book man uscript titled "The City in Time: Contemporary Art and Urban Form in Vietnam and Cambodia."

1. T. K. Sabapathy, Road to Nowhere: The Quick Rise and the Long Fall of Art History in Singapore (Singapore: National Institute of Education, Nanyang Technological University, 2010), 18. 2. He also taught Asian art at Farnham School of Art, Surrey, in 1966 - the first such appointment in the British school and college system-and at St Martins School of Art in 1969-70.

3. Sabapathy, Road to Nowhere, 26. The books he encountered are Philip Rawson, The Art of Southeast Asia: Cambodia, Vietnam, Thailand, Laos, Burma, Java, Bali (1967; repr., London: Thames and Hudson, 2002), and Claire Holt, Art in Indonesia: Continuities and Change (Ithaca, NY: Cornell University Press, 1967).

4. Sabapathy, Road to Nowhere, 32.

5. See, for example, Richard Meyer, What Was Contemporary Art? (Cambridge, MA: MIT Press, 2013).

6. See Thierry de Duve, "When Form Has Become Attitude and Beyond," in Theory in Contemporary Art since 1985, ed. Zoya Kocur and Simon Leung (Chichester, UK: John Wiley \& Sons, 2013), 21-33.

7. Such works on Europe include Dipesh Chakrabarty, Provincializing Europe: Postcolonial Thought and Historical Difference (Princeton, NJ: Princeton University Press, 2000), and Iftikhar Dadi and Salah Hassan, eds., Unpacking Europe: Towards a Critical Reading (Rotterdam, the Netherlands: Museum Boijmans Van Beuningen, 2001).

8. Comparable figures include Australia-based art historian John Clark, renowned for establishing a formative comparative approach to modern art in Asia, and Stanley J. O'Connor, the first professor of Southeast Asian art history appointed at a university in the United States, but neither wrote exclusively on modern and contemporary Southeast Asian art, nor have similar anthologies of their work been published.

\section{Katalin Cseh-Varga \\ Eastern European Art Histories of Interconnectedness}

Klara Kemp-Welch. Networking the Bloc: Experimental Art in Eastern Europe, 1965-1981. Cambridge, MA: MIT Press, 2019. 480 pp.; 36 color ills., 198 b/w. \$49.95

Those familiar with Klara Kemp-Welch's work have long awaited Networking the Bloc: Experimental Art in Eastern Europe, 1965-198I, the result of years-long and exhaustive research-research that led to travel through many European countries and even overseas, like many of the protagonists in this book. Kemp-Welch tells stories of Eastern European art during the Cold War that cross national borders and ideological boundaries. This "collection of interconnected stories"

(5) intends to overcome stereotypical histo ries of experimental art in state socialisms as isolated and oppositional. ${ }^{1}$ Kemp-Welch instead seeks to understand the bottom-up processes and agency of art networks and experimental art's internationally oriented distribution centers, strategies, and media. The intention was not to write individual or purely national historiographies: Networking the Bloc is a narrative composed of connections, crossroads, encounters, and ideas that reach from Central Europe to Latin America. We recognize a networking temperament reflected, as well, in the arrangement of stories and the cross-referenced writing style of Kemp-Welch. Because of this structure, each chapter can be read independently.

The book is a companionable guide through the complex transnational art worlds of Eastern Europe between the mid-1960s and the end of the 1970s. Recent years have seen significant new scholarship treating the subject from multiple perspectives beyond those of Cold-War or nation-state division, but Networking the Bloc comes with the synthetic coherence a monograph can provide. The book deconstructs myths of countercultural, Communist Party-opposing, neoavant-gardists and reveals that artists were able to network internationally despite constraints on travel or communication (315).

Networking the Bloc is divided into three comprehensive parts. The first looks at "initiatives that brought about collective mobili- zation" and is mostly focused on "dialogues and projects" (I3); the second is devoted to the creation of passages for "people and objects" (I43) that lead to further expansion of the network; and the third is devoted to convergences "within the framework of shared exhibitions and events" and media (279). Kemp-Welch begins to works herself through the mobilization of a network, in part one, by looking at the friendship of the French critic Pierre Restany and the Slovak artist Alex Mlynárčik, which, starting in 196I, provided Czechoslovak and Polish artists with information on trends and initiatives in the Western arts scene, while simultaneously opening up the possibility of having their work presented in Paris. The critic believed in the "idea of the united Europe" (38) and worked to overcome the Western domination of European art scenes. The main protagonists of Kemp-Welch's next case study are the Czechs Jindrich Chalupecký and Milan Knížák. Critic and theoretician Chalupecký became a key networker, with the aim of promoting contemporary art in Czechoslovakia. Partly through the support of Chalupecký, Knížák, an artist with an event-based practice meant to evoke change in people's lives, became internationally known, mobile, and well-connected. From interpersonal contacts Kemp-Welch then moves to the medium of mail art, as manifest in the book Mail art, communication á distance, concept ( 1971) and a follow-up exhibition in the same year at the VII Biennale de Paris and in Belgrade and Zagreb. To artists like Petr Štembera, Gyula Konkoly, and Endre Tót, participation meant the possibility of global communication and a pathway to international recognition. The author next presents the NET initiative: a call for democratic and self-managing artistic exchange formulated by Polish artists Jarosław Kozłowski and Andrzej Kostołowski in 1971 : "NET sought to bypass existing art world mechanisms by proposing a field in which artists could distribute their ideas freely" ( Iо०). As both the mail-art book and exhibition and the NET proposal show, most of the communication in experimental art circles was in writing, through the mail, as was the case for Klaus Groh's preparation of the book Aktuelle Kunst in Osteuropa (1972), which featured Czechoslovak, Polish, Hungarian, Soviet, Bulgarian, and Yugoslav artists. The author argues that "Groh's book marked a change. It became clear that the indepen- 